\title{
Use of slide latex agglutination test for rapid diagnosis of vaginal candidosis
}

\author{
R RAJAKUMAR, ${ }^{*}$ C J N LACEY,* E G V EVANS, $\uparrow$ AND J A CARNEY $\ddagger$ \\ From the *Department of Genitourinary Medicine, General Infirmary, the †Department of Microbiology, \\ University of Leeds, and the Regional Mycology Laboratory, General Infirmary, Leeds, and $¥ M e r c i a$ \\ Diagnostics Ltd, West Byfleet, Surrey
}

SUMMARY A new slide latex agglutination test was compared with microscopy and culture for diagnosing vaginal candidosis in 367 women attending a genitourinary medicine clinic. Vaginal candidosis occurred in $10 \%$ of the patients, and $7 \%$ had commensal carriage of Candida spp. The slide latex agglutination test was superior to microscopy in immediate diagnosis and was rapid and simple to perform. Of the patients with vaginal candidosis, $72 \%$ were detected by slide latex agglutination test compared with $38 \%$ by microscopy. The test discriminated well between patients yielding cultures of Candida spp who had symptoms and signs and those who showed commensal carriage.

\section{Introduction}

Vaginal candidosis is the most commonly reported genital infection in women attending genitourinary medicine and sexually transmitted disease clinics. ${ }^{1}$ In Britain in 1983 almost 50000 cases of candidosis were reported. The immediate diagnosis of vulvovaginal candidosis is based on symptoms and signs usually supplemented by microscopical examination of vaginal smears. Microscopy alone is a relatively insensitive aid to diagnosis, and several reports showed only $36 \%$ to $43 \%$ correlation with candidosis. ${ }^{2-4}$ The development of a slide latex agglutination test for detection of candidal antigens has provided an alternative method for diagnosing vaginal candidosis, ${ }^{5}$ and we have previously evaluated this test in a laboratory setting. ${ }^{4}$ We wished to extend our observations by using this rapid test in a clinic and evaluating its performance against conventional diagnostic criteria.

This work was presented in part to the Spring Meeting of the Medical Society for the Study of Venereal Diseases held in Brighton in May 1986.

Address for reprints: Dr C J N Lacey, Department of Genitourinary Medicine, The Blundell Street Clinic, General Infirmary, Leeds LS1 3EX

Accepted for publication 27 September 1986.

\section{Patients and methods}

The study population consisted of 367 consecutive women attending the department of genitourinary medicine at the General Infirmary, Leeds, in July and August 1985. A standard history was recorded, and genital examination performed. Special attention was paid to symptoms of itching and soreness, signs of vulvovaginitis, mucosal oedema, and the presence and nature of vaginal discharge. Investigations included serological tests for syphilis, culture for Neisseria gonorrhoeae, Trichomonas vaginalis, and Chlamydia trachomatis, and cervical cytology. Vaginal specimens were directly innoculated, using a $10 \mu l$ loop, on to Sabouraud's dextrose agar containing chloramphenicol $(0.05 \mathrm{~g} /)$ and incubated at $37^{\circ} \mathrm{C}$. Yeasts that developed at 24 and 48 hours were identified using the germ tube test ${ }^{6}$ and the API 20C Aux Yeast Identification System (API Laboratory Products, Basingstoke, England). The quantity of yeast recovered in culture was recorded as the number of colony forming units. Vaginal smears were examined after staining by Gram's method and also by phase contrast microscopy.

\section{SLIDE LATEX AGGLUTINATION TEST}

The candidal test latex reagents consisted of polystyrene latex particles coated with purified immunoglobulins derived from a rabbit antiserum 
raised against partially purified cell wall fractions of Candida albicans serotypes A and B and Candida glabrata (Torulopsis glabrata). ${ }^{4}$ The sensitivity of the test latex reagent, determined against $C$ albicans serotype A cell wall mannan ${ }^{7}$ diluted in glycine buffered saline (GBS) pH $8 \cdot 2$, was $25 \mathrm{ng} / \mathrm{ml}$.

The slide latex agglutination test reagents consisted of a candidal test latex and a negative control latex coated with preimmune rabbit gammaglobulins. Specimens were taken with a swab (Culturette, Marion Scientific, Kansas City, USA) from the lateral vaginal walls of the women.Each swab was immersed in $400 \mu$ l of GBS contained in a small tube, left to stand for 30 seconds, and then squeezed out into the buffer. The swab was discarded, and the residual fluid used for testing.

A drop of candidal test latex was placed in one demarcated area of a black backed glass slide, and a drop of control latex was placed in an adjacent area . One drop $(50 \mu \mathrm{l})$ of vaginal specimen in GBS was added to the test and control latex and mixed for 15 seconds with a wooden applicator stick. The slide was gently rocked for 90 seconds and observed for agglutination .

The incorporation of a negative control was useful, and about $5 \%$ of vaginal specimens gave non-specific reactions with both test and control latex .Candida spp were not recovered from any of the women who gave this non-specific reaction with the latex, and these results were included as negative in the analysis of results. We found that an observation time of 90 seconds was most useful, as more samples showed fine granularity or other non-specific changes if observation was prolonged.

\section{ANALYSIS OF DATA}

The diagnostic investigations that were compared in this study comprised microscopy of vaginal specimens, conventional culture on Sabouraud's agar, and the slide latex agglutination test. To make valid comparisons, it was necessary to define the condition vaginal candidosis. Differing views on its definition exist, ${ }^{8}$ but in this study characteristic symptoms of candidosis were taken to be pruritis and soreness, and typical signs were vulvitis, vaginitis, and vaginal discharge. Patients with these symptoms or signs in whom microscopy or culture gave positive results were defined as having vaginal candidosis; patients without symptoms or signs whose cultures for Candida spp were positive were regarded as having commensal carriage. This was considered to reflect the most widely accepted current view of the dual role of Candida spp as pathogens and commensals in the vagina.

Microscopy and slide latex agglutination were compared for their sensitivity, specificity, predictive value positive, predictive value negative, and efficiency in diagnosing vaginal candidosis.

\section{Results}

A total of 367 women were evaluated on 371 occasions in July and August 1985. None of the women had been treated for candidosis in the recent past. Cultures for Candida spp were positive in 63 of 371 presentations; an incidence of $17 \%$. In $37(59 \%)$ of 63 patients with positive cultures there was clinical evidence of candidosis. Thus $10 \%$ of the study population had vaginal candidosis and $7 \%$ carried Candida spp as commensals.

The slide latex agglutination test gave positive results on 37 occasions. In 30 of these instances candidal cultures were positive concurrently, in two women cultures were negative but had been positive seven days previously, and on five occasions (four patients) there was no evidence of Candida spp. The diagnoses for these four patients were gonorrhoea, chlamydial infection, non-specific genital infection, and no abnormality detected. The slide latex agglutination test was much more commonly positive in women with candidosis than in those with commensal carriage. Of the 30 women yielding positive slide latex agglutination test results and culture for Candida spp, 28 (93\%) had signs and symptoms of candidosis. Table I shows the full results, including those of microscopical examination of vaginal smears. Two patients with signs and symptoms of candidosis who were positive on microscopy, were slide latex agglutination and culture negative.

The most useful observation from these data was the effectiveness of the slide latex agglutination test compared with microscopy in diagnosing vaginal candidosis. Table II shows that the slide latex agglutination test was almost twice as sensitive as microscopy in detecting vaginal candidosis.Its overall efficiency was also superior to that of microscopy.

We also compared the quantity of yeasts isolated with the results of the slide latex agglutination test (table III). Consistently more colonies of yeast were isolated from women with a positive slide latex agglutination test result than from those with a negative

TABLE I Comparison of microscopy, slide latex agglutination (SLA) test, and culture in 371 patient visits

\begin{tabular}{|c|c|c|c|c|c|c|c|}
\hline \multirow[b]{2}{*}{ Diagnosis } & \multirow[b]{2}{*}{ No } & \multicolumn{2}{|c|}{ Microscopy } & \multicolumn{2}{|c|}{ SLA test } & \multicolumn{2}{|c|}{ Culture } \\
\hline & & + & - & + & - & + & - \\
\hline $\begin{array}{l}\text { Vaginal candidosis } \\
\text { Commensal carriage } \\
\text { Negative }\end{array}$ & $\begin{array}{r}39 \\
26 \\
306\end{array}$ & $\begin{array}{r}15 \\
2 \\
3\end{array}$ & $\begin{array}{r}24 \\
24 \\
303\end{array}$ & $\begin{array}{r}28 \\
2 \\
7\end{array}$ & $\begin{array}{r}11 \\
24 \\
299\end{array}$ & $\begin{array}{r}37 \\
26 \\
0\end{array}$ & $\begin{array}{r}2 \\
0 \\
306\end{array}$ \\
\hline
\end{tabular}

$+=$ positive,$-=$ negative test results. 
TABLE II Comparison of microscopy and slide latex agglutination (SLA) test in the diagnosis of vaginal candidosis

\begin{tabular}{lll}
\hline & Microscopy & SLA test \\
\hline Sensitivity (\%) $\left(\frac{a}{a+b} \times 100\right)$ & 38.5 & 71.8 \\
Specificity (\%) $\left(\frac{d}{c+d} \times 100\right)$ & 98.5 & 97.3 \\
Predictive value positive (\%) $\left(\frac{a}{a+c} \times 100\right)$ & 75.0 & 75.7 \\
Predictive value negative (\%) $\left(\frac{d}{b+d} \times 100\right)$ & 93.2 & 96.7 \\
Efficiency (\%) $\left(\frac{a+d}{a+b+c+d} \times 100\right)$ & 92.2 & 94.6 \\
\hline
\end{tabular}

$a=$ No with vaginal candidosis and positive results on microscopy (15) or SLA (28).

$b=$ No with vaginal candidosis and negative results on microscopy (24)or SLA (11).

$c=$ Total with commensal carriage or negative for Candida spp and positive results on microscopy (5) or SLA (9).

$\mathrm{d}=$ Total with commensal carriage or negative for Candida spp and negative results on microscopy (327) or SLA (323).

slide latex agglutination test result. This reflects the fact that larger numbers of yeasts were recovered from patients with candidosis than from those with commensal carriage.

\section{Discussion}

The diagnosis of vaginal candidosis is based on history and examination and is usually supplemented by either microscopy or culture of vaginal specimens, or both . The definition and criteria for diagnosing cases of vaginal candidosis, however, vary substantially. ${ }^{9}$ This reflects differing views as to whether Candida spp may be commensal in the vagina or are always associated with some morbidity ${ }^{8}$ We and many others think that when women are routinely tested by culture, the isolation of Candida spp is not always associated with clinical presentations and signs..$^{340}$

In this study a new slide latex agglutination test was assessed in a busy genitourinary medicine clinic. The test was carried out by examining doctors and was rapid and simple to perform. The test was useful for

TABLE III Quantity of yeast isolated on culture compared with result of slide latex agglutination (SLA ) Yest

\begin{tabular}{lll}
\hline $\begin{array}{l}\text { No of yeast } \\
\text { colonies }\end{array}$ & $\begin{array}{l}\text { No of patients } \\
\text { with positive } \\
\text { in culture }\end{array}$ & $\begin{array}{l}\text { No of patients } \\
\text { with negative } \\
(n=30)\end{array}$ \\
\hline$>200$ & 7 & $\begin{array}{l}\text { SLA test result } \\
(n=33)\end{array}$ \\
$30-200$ & 5 & 0 \\
$10-29$ & 17 & 3 \\
$<10$ & 1 & 14 \\
\hline
\end{tabular}

diagnosis ,and its sensitivity was high (72\%)compared with that of microscopy (39\%). The result of the slide latex agglutination test was available immediately, and was useful for managing patients. The slide latex agglutination test discriminated well between patients with vaginal candidosis and those whose subsequent cultures of Candida spp suggested commensal carriage.

The study also confirmed the association noted in our previous work between the quantity of yeast recovered and the patient's clinical status. ${ }^{4}$ The greater the quantity of yeast recovered the more likely was the patient to have symptoms and signs related to candidosis. The slide latex agglutination test was also more likely to give positive results when greater quantities of yeast were isolated and thus may be "load sensitive".

This study showed that a slide latex agglutination test that detects soluble cell wall antigens of Candida spp is useful in diagnosing vaginal candidosis. It is easy to perform, requires only a small amount of bench space, and needs no specialised equipment.Agglutination of the latex is clearly visible and takes place in as little as 10 seconds in some samples, though a gradual and progressive change in one to one and a half minutes is more usual. Slide latex agglutination is superior to microscopy in immediate diagnosis. It could be used as a useful adjunct to current methods, and would be specially useful where immediate microscopy is not available.

We thank the staff of the Blundell Street Clinic and the Regional Mycology Laboratory for their help and cooperation. 


\section{References}

1. Anonymous. Sexually transmitted disease surveillance in Britain 1983. Br Med J 1985;291:528-30.

2. Thin RNT, Atia W, Parker JDJ, Nicol CS, Canti G. Value of Papanicolau-stained smears in the diagnosis of trichomoniasis, candidiasis, and cervical herpes simplex virus infection in women. British Journal of Venereal Diseases 1975;51:116-8.

3. Willmott FE. Genital yeasts in female patients attending a VD clinic. British Journal of Venereal Diseases 1975;51:119-22.

4. Evans EGV, Lacey CJN, Carney JA. Criteria for the diagnosis of vaginal candidosis: evaluation of a new latex agglutination test. Eur J Obstet Gynaecol Reprod Biol 1986;22:365-71.

5. Hopwood V, Evans EGV, Carney JA. Rapid diagnosis of vaginal candidosis by latex particle agglutination. J Clin Pathol
1985;38:455-8.

6. Taschdjian CL, Burchall JJ, Kozinn PJ. Rapid identification of Candida albicans by filamentation on serum and serum substitutes. Am J Dis Child 1960;99:212-5.

7. Peat S, Whelan WJ, Edwards TE. Polysaccharide of bakers' yeast. Part IV: Mannan. J Chem Soc 1961;1:29-34.

8. Odds FC. Candida and candiosis. Leicester: Leicester University Press, 1979:101-12.

9. O'Connor BH, Adler MW. Current approaches to the diagnosis, treatment, and reporting of trichomoniasis and candidosis. British Journal of Venereal Diseases 1979;55:52-7.

10. Goldacre MJ, Watt B, Loudon N, Milne LJR, Loudon JDO, Vessey MP. Vaginal microbial flora in normal young women. Br Med J 1979;i:1450-3. 